\title{
Coulisses
}

Revue de théâtre

\section{Le jeune théâtre universitaire libre de Bruxelles}

\section{F. Clarinval et Rédaction}

\section{OpenEdition}

\section{Journals}

Édition électronique

URL : http://journals.openedition.org/coulisses/1639

DOI : $10.4000 /$ coulisses.1639

ISSN : 2546-9460

\section{Éditeur}

Presses universitaires de Franche-Comté

\section{Édition imprimée}

Date de publication : 1 février 1991

Pagination : 28-29

ISSN : 1150-594X

\section{Référence électronique}

F. Clarinval et Rédaction, «Le jeune théâtre universitaire libre de Bruxelles », Coulisses [En ligne], 3 | Hiver 1991, mis en ligne le 04 juillet 2017, consulté le 23 octobre 2019. URL : http:// journals.openedition.org/coulisses/1639; DOI : 10.4000/coulisses.1639

Ce document a été généré automatiquement le 23 octobre 2019

Coulisses 


\title{
Le jeune théâtre universitaire libre de Bruxelles
}

\author{
F. Clarinval et Rédaction
}

$1 \quad$ Pouvez vous nous présenter le JTULB?

2 Tout d'abord, il faut savoir que "libre" en Belgique veut dire anticlérical. Le JTULB existe depuis les années quarante avec des périodes creuses. Des noms prestigieux sont passés au JTULB, des metteurs en scène passent et se professionnalisent.

3 Quelle est la recherche de la troupe actuelle? Comment fonctionnez-vous?

4 Notre recherche est de définir une spécificité d'une pratique universitaire liée au théâtre; qu'est-ce-que le TU?, comment sortir ou non du milieu professionnel / amateur / semi-professionnel ?... Notre troupe essaie de sortir de ces clivages en montrant qu'un théâtre amateur peut, au sein de l'Université, produire un travail théâtral exigeant dans ses moyens et dans la formation des acteurs. On fait avec du bric et du broc; il y a des étudiants et des anciens étudiants, on arrive à constituer une équipe théâtrale fonctionnant plus ou moins de manière collégiale. C'est les conditions du TU!

Comment en étes-vous venu à monter Les Nègres?

6 C'est le quatrième spectacle actuellement. La pièce est en fait une histoire un peu tortueuse, dans la mesure où la commission culturelle de l'Université nous avait proposé, dans le cadre du Bicentenaire de la Révolution Française, de monter un spectacle. Or nous avions envie de parler d'une autre révolution, de quelque chose d'actuel, parce que ressasser la Révolution française... ! C'est par ce biais là que nous avons choisi Genet et Les Nègres, car ce texte traite du renversement du pouvoir blanc par une révolte noire. Il a été écrit en 1959, période où les pays occidentaux connaissent des renversements dans leurs colonies d'Afrique. Ce texte est donc politique dans son contexte de production; Genet est très lyrique on ne peut donc pas parler de texte politique comme Brecht peut en écrire. Nous n'avions pas envie de jouer Genêt avec tous les clichés : homosexuel, tôlard... Nous avions envie de montrer que 
sous ces clichés se cache un autre Genet si on contextualise son écriture, c'est le Genet politique.

Votre recherche est donc politique mais basée principalement sur le théâtre et le racisme?

Nous essayons de développer toute une réflexion sur ce thème. Qu'est-ce que le théâtre peut dire par rapport au racisme? Nous avons monté l'année dernière Têtes rondes et Têtes pointues de Brecht, texte qui traite de la montée du racisme en Allemagne et montre les mécanismes sociaux qui amènent au racisme. (Nos comédiens étaient chauves avec un carré rouge pour les différencier). Les Nègres s'inscrivent dans notre travail.

9 Le problème du racisme est un sujet brûlant: pour venir en France, trois de nos comédiens, étrangers de nationalité (une Mauricienne, et deux Marocains), ont obtenu leur visa avec difficultés. Comme l'Université est un espace de liberté et que nous ne sommes pas pris par des raisons commerciales, c'est le lieu par excellence où l'on peut soulever des problèmes. C'est encore une des raisons pour lesquelles nous avons monté Genêt : il nous montre comment fonctionnent les clichés raciaux et sociaux.

Vous ne vous êtes pas formalisés de l'interdiction de Genet de faire iouer cette pièce par des blancs?

11 C'est une interdiction mythique qui plane, mais ce n'est pas incontournable, d'autant plus que nous essayons de produire un théâtre de signes; on peut en se grimant jouer les noirs. Notre position d'étudiant nous autorise encore à attaquer ce mythe.

Vous êtes quand même restés fidèles au texte?

Oui, mais si l'on ne voit pas le contexte de production, on oublie cet aspect politique. Jouer Genêt est intéressant au niveau théâtral, si on essaie de trouver la façon dont on va redonner un sens politique au texte.

Comment avez-vous procédé?

Notre metteur en scène a fixé la fiction de base : des noirs représentent Les Nègres à la frontière Sud-Africaine. Pour cela, entre les spectateurs et les acteurs, des barbelés indiquent le camp militaire et établissent la distance. Sur la gauche de la scène, toute une série de bidons sur laquelle s'installe la cour, constituée des différents pouvoirs occidentaux blancs - la reine, le gouverneur, le missionnaire et son valet (nous avons mis deux valets au lieu d'un) - et sur la droite, se trouve l'espace des nègres, habillés en militaires, et constitué de matériel militaire. Cette fiction ancre le texte dans une actualité immédiatement perceptible grâce au panneau indicateur "South Africa », et permet au spectateur de réinjecter du politique au texte.

Il y a aussi ce fameux ailleurs, présent de façon régulière, et qui est devenu pour nous un « MP » : une personne qui intervient sur scène de façon récurante pour dire « on est en train de juger quelqu'un, ailleurs, là-bas ». Cet ailleurs peut vite devenir un ailleurs poétique ou métaphysique qui n'a pas de consistance, mais quand ce spectacle a été monté, il nous semblait évident qu'il avait un poids réel pour un spectateur de l'époque. 


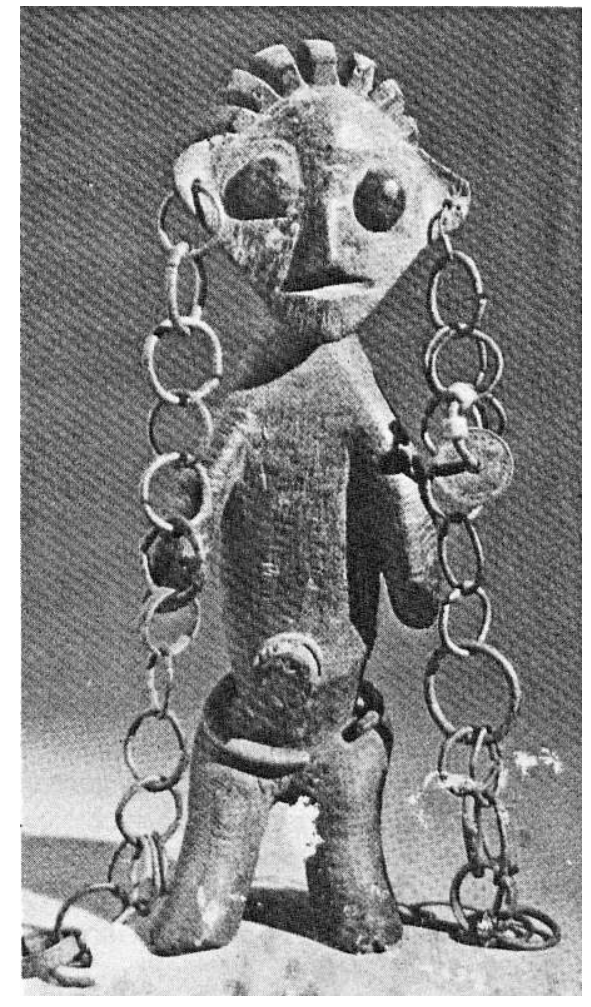

\section{AUTEURS}

F. CLARINVAL

Comédien du TULB 